\title{
Pengaruh Pelatihan Efikasi Diri terhadap Keterikatan Kerja Perawat Rumah Sakit Umum Daerah di Sulawesi Selatan
}

\author{
Dewi Tri Resky Yanti ${ }^{1}$ \\ Fuad Nashori \\ Faraz \\ Magister Psikologi Profesi Universitas Islam Indonesia
}

\begin{abstract}
This study aims to determine the effect of self-efficacy training on work engagement of nurses at regional general hospital in South Sulawesi. The hypothesis of this study is self-efficacy training can improving work engagement of nurses at regional general hospital in South Sulawesi. The subjects of this study were 12 nurses, 6 nurses for the experimental group and 6 nurses for the control group from four care rooms: interna (I and VII), child (II), and surgical (V) with civil service status the hospital is at least 1 year, minimum education D3 Nursing and has a level of work engagement included in the category of medium. This study used the scale of work engagement (UWES) adapted by Christian, Hastjarjo, Ancok, and Meiyanto (2013) and the self-efficacy scale compiled by Valentino and Himam (2013) using self-efficacy dimensions expressed by Bandura $(1977,1986)$. This research is a quasi experimental research with non-randomized pretest-posttest control group design using Mann-Whitney and Friedman's test analysis technique. The result of data analysis showes that the hypothesis was rejected.
\end{abstract}

Keywords: nurses. self-efficacy training, work engagement.

\begin{abstract}
Abstrak: Penelitian ini bertujuan untuk mengetahui pengaruh pelatihan efikasi diri terhadap keterikatan kerja pada perawat rumah sakit umum daerah di salah satu kabupaten di Sulawesi Selatan. Hipotesis penelitian adalah pelatihan efikasi diri berpengaruh dalam meningkatkan keterikatan kerja perawat rumah sakit umum daerah di salah satu kabupaten di Sulawesi Selatan. Subjek penelitian ini berjumlah 12 perawat, masing-masing 6 perawat untuk kelompok eksperimen dan 6 perawat untuk kelompok kontrol dari ruang perawatan internal (I dan VII), anak (II), dan bedah (V) yang berstatus pegawai negeri sipil, telah bekerja di rumah sakit tersebut minimal 1 tahun, pendidikan minimal D3 Keperawatan dan memiliki tingkat keterikatan kerja yang termasuk dalam kategori sedang. Penelitian ini menggunakan skala keterikatan kerja (UWES) yang diadaptasi oleh Christian, Hastjarjo, Ancok, dan Meiyanto (2013) dan skala efikasi diri yang disusun Valentino dan Himam (2013) menggunakan dimensi efikasi diri yang diungkapkan Bandura $(1977,1986)$. Penelitian ini merupakan penelitian kuasi eksperimen dengan desain eksperimen ulang non-random (non-randomized pretest-posttest control group design) menggunakan teknik analisis data uji Mann-Whitney dan Friedman. Hasil analisis data menunjukkan bahwa hipotesis penelitian ditolak.
\end{abstract}

Kata Kunci : keterikatan kerja, pelatihan efikasi diri, perawat

\footnotetext{
${ }^{1}$ Korespondensi mengenai isi artikel ini dapat dilakukan melalui: dewianwar57@yahoo.co.id
} 
Perawat sebagai sumber daya manusia yang memegang peranan penting dalam memberikan pelayanan di rumah sakit diharapkan dapat membangun hubungan yang baik dengan pasien, membangun empati dengan pasien, dan mempunyai keterikatan dengan pekerjaannya (Daderman \& Basinska, 2016). Kesadaran akan pentingnya faktor keterikatan kerja dalam organisasi, termasuk rumah sakit kini tengah berkembang di beberapa negara. Keterikatan kerja merupakan prediktor penting dalam perfomansi pelayanan kesehatan yang sangat berkualitas (Mache, Vitzhum, Wanke, Groneberg, Klapp, dan Danzer 2012).

Keterikatan kerja memegang peran penting dalam organisasi sebab dapat membantu upaya optimalisasi peran karyawan dalam menjalankan roda organisasi (Davids, 2011). Keterikatan kerja merupakan motivasi afektif yang terdiri atas aspek semangat (vigor), dedikasi (dedication), dan penghayatan (absorption) (Schaufeli dan Bakker, 2003). Karyawan yang mempunyai keterikatan kerja akan lebih puas dengan pekerjaannya, kemudian memiliki komitmen yang tinggi terhadap organisasi, dan tidak memiliki keinginan untuk meninggalkan organisasi. Keterikatan kerja yang tinggi berdampak pada tingginya komitmen dan kepuasan, rendahnya ketidakhadiran dan keinginan untuk keluar, memiliki tingkat kesejahteraan psikologis yang lebih baik, dan kinerja yang lebih baik. Namun, untuk mencapai karyawan dengan keterikatan kerja yang tinggi bukanlah hal yang mudah (Alzyoud, Othman, dan Isa, 2014).

Data dari Badan Pengembangan dan Pemberdayaan Sumber Daya Manusia Kesehatan (Kemenkes RI, 2016) menunjukkan bahwa secara nasional, rasio perawat pada tahun 2015 adalah 87,65 per 100.000 penduduk. Angka tersebut masih jauh dari target tahun 2019 yaitu 180 per 100.000 penduduk. Angka tersebut juga menunjukkan bahwa target tahun 2014 (sebesar 158 per 100.000) belum tercapai. Secara khusus di provinsi Sulawesi Selatan, rasio perawat hanya mencapai angka 131,15. Meskipun telah melebihi angka rasio secara nasional, namun masih jauh dari angka rasio target Nasional tahun 2019.

Studi pendahuluan, di rumah sakit umum daerah di salah satu kabupaten di Sulawesi Selatan, menyebutkan bahwa selain menjalankan tugas melayani pasien dan keluarga pasien, perawat juga dituntut mengerjakan tugas lain, seperti administrasi, logistik, masalah gizi, dan penyerahan obat ke pasien. Dalam studi juga ditemukan ada beberapa perawat yang memberikan pelayanan kurang baik kepada pasien, misalnya berbicara dengan ketus, baik terhadap pasien maupun keluarga pasien. Banyak perawat kurang disiplin dan kurang fokus dalam melaksanakan pekerjaannya, dan tidak sedikit yang mengalami perselisihan dengan perawat lain.

Hasil wawancara dengan sembilan perawat di ruang perawatan internal: unit anak dan bedah menunjukkan bahwa perawat mengalami kelelahan kerja akibat beban pekerjaan yang berat dan sifat pekerjaan yang monoton. Hasil survei terhadap 58 perawat di rumah sakit yang sama diperoleh data: perawat yang memiliki keterikatan kerja rendah sebesar 12,08 persen, kemudian yang berkategori sedang sebesar 75,86 persen, terakhir berkategori tinggi sebesar 12,06 persen. Informasi tersebut menunjukkan bahwa perawat yang memiliki keterikatan kerja rendah dan sedang jauh lebih banyak dibandingkan yang memiliki keterikatan kerja tinggi. Hal ini menarik untuk diteliti lebih jauh dan perlu menjadi perhatian pihak rumah sakit untuk menyusun langkah perbaikkan atau pemberdayaan terutama dari unsur sumberdaya manusia (perawat).

Penelitian Xanthopoulou, Bakker, Demerouti, dan Schaufeli (2008) 
menyatakan bahwa sumberdaya pekerjaan (job resources) dan sumberdaya pribadi (personal resources) berhubungan positif dengan keterikatan kerja. Bakker dan Demerouti (2008) mengemukakan bahwa sumberdaya pekerjaan meliputi dukungan sosial dari rekan kerja dan supervisor, umpan balik terhadap kinerja, variasi keahlian, otonomi, dan kesempatan belajar. Sumberdaya pribadi meliputi optimisme, efikasi diri, harga diri, resiliensi, dan gaya coping aktif yang dapat membantu karyawan dalam kontrol dan berdampak pada kesuksesan dalam lingkungan kerja dan mencapai kesuksesan karir.

Loeb (2016) menyatakan bahwa efikasi diri merupakan salah satu sumberdaya pribadi yang terpenting dalam dunia kerja. Efikasi diri berpengaruh terhadap keterikatan kerja (Xanthopoulou, Bakker, Demerouti, dan Schaufeli, 2007; Xanthopoulou, Bakker, Heuven, Demerouti, \& Schaufeli, 2008; Hayuningtyas \& Helmi, 2015). Apabila dibandingkan dengan sumberdaya pribadi lainnya, khususnya optimisme, efikasi diri memiliki pengaruh yang lebih besar terhadap keterikatan kerja (Putri, Priyatama, \& Karyanta, 2015). Bakker dan Schaufeli (2014) menyatakan bahwa salah satu strategi pengembangan yang dapat dilakukan organisasi untuk meningkatkan keterikatan kerja adalah program pelatihan berfokus pada pengembangan efikasi diri pada karyawan. Mache, Vitzhum, Xanthopoulou, Bakker, dan Fiscbach (2013) juga menyarankan bahwa diperlukan pelatihan untuk meningkatkan efikasi diri agar dapat memfasilitasi karyawan dalam menangani aspek-aspek interaksi pelayanan terhadap pelanggan secara efektif dan tetap terikat. Peningkatan efikasi diri efektif terutama untuk mengurangi atau menurunkan tingkat tuntutan emosional dan disonansi yang dianggap hampir tidak mungkin tidak terjadi dalam konteks pekerjaan tertentu, khususnya dalam bidang pelayanan.
Berdasarkan pemaparan di atas, permasalahan yang hendak dibahas dalam penelitian ini adalah "apakah pelatihan efikasi diri berpengaruh terhadap keterikatan kerja perawat rumah sakit umum daerah di salah satu kabupaten di Sulawesi Selatan?"

Penelitian ini bertujuan untuk mengetahui pengaruh pelatihan efikasi diri terhadap keterikatan kerja pada perawat rumah sakit umum daerah di salah satu kabupaten di Sulawesi Selatan. Penelitian ini diharapkan dapat memberikan sumbangan wawasan terkait keterikatan kerja dan salah satu jenis intervensi yang dapat meningkatkan keterikatan kerja pada pada perawat rumah sakit. Penelitian ini diharapkan dapat memberikan informasi kepada pihak rumah sakit mengenai gambaran level keterikatan kerja perawat khususnya di rumah sakit tersebut dan memberikan masukan rumah sakit mengenai cara meningkatkan level keterikatan kerja perawat.

Keterikatan kerja diartikan sebagai kondisi pikiran yang positif, memuaskan, dan berhubungan dengan pekerjaan. Kondisi tersebut ditandai dengan aspek semangat, dedikasi, dan penghayatan. Apabila dibandingan dengan kondisi sesaat dan spesifik, keterikatan kerja mengacu pada kondisi afektif-kognitif yang lebih persisten dan pervasif yang tidak berfokus pada objek, peristiwa, individu, atau perilaku tertentu. Keterikatan kerja merupakan kondisi karyawan yang ditandai dengan tingkat energi yang tinggi dan identifikasi yang kuat dengan pekerjaannya (Schaufeli dan Bakker, 2003).

Ada tiga aspek keterikatan kerja, yakni (1) Semangat (vigor), yakni tingginya tingkat energi dan mental karyawan ketika bekerja, keinginan karyawan untuk menunjukkan usaha dalam pekerjaan, dan ketekunan (persistensi) bahkan dalam menghadapi kesulitan; (2) Dedikasi (dedication), yakni keterlibatan kuat karyawan dengan 
pekerjaannya, memiliki pengalaman merasa penting, antusiasme, inspirasi, kebanggaan, dan tantangan; (3) Penghayatan (absorption), yakni kondisi karyawan yang terkonsentrasi sepenuhnya dan merasakan bahagia dengan pekerjaannya, waktu terasa cepat berlalu ketika bekerja, dan mengalami kesulitan untuk memisahkan diri dari pekerjaannya (Schaufeli dan Bakker (2003).

Faktor-faktor yang mempengaruhi keterikatan kerja menurut Bakker dan Demerouti (2008) ada dua dan dapat dijelaskan sebagai berikut: (1) Sumberdaya pekerjaan (job resources), meliputi dukungan sosial dari rekan kerja dan supervisor, umpan balik terhadap kinerja, variasi keahlian, otonomi, dan kesempatan belajar. Sumberdaya pekerjaan merupakan dimensi-dimensi fisik, sosial, dan pekerjaan pada pekerjaan yang dapat mengurangi dampak dari tuntutan pekerjaan dan psikologis, bersifat fungsional dalam pencapaian target kinerja, dan menstimulasi pengembangan diri, pembelajaran, dan perkembangan (Schaufeli dan Bakker, 2004); (2) Sumberdaya pribadi (personal resources), meliputi optimisme, efikasi diri, harga diri, resiliensi, dan gaya coping aktif yang dapat membantu karyawan dalam kontrol dan berdampak pada kesuksesan dalam lingkungan kerja dan mencapai kesuksesan karir. Sumberdaya pribadi merupakan evaluasi diri yang positif dan terhubung dengan resiliensi dan efikasi diri (Hobfoll, Johnson, Ennis dan Jackson, 2003).

Efikasi diri pertama kali diperkenalkan Albert Bandura pada 1986 dengan menggunakan teori belajar sosial (kemudian dikenal dengan teori kognitif sosial). Efikasi diri merupakan keyakinan individu terhadap kemampuan yang dimiliki untuk memobilisasi motivasi, sumber daya kognitif dan afektif, serta rangkaian tindakan yang diperlukan untuk mengendalikan tuntutan lingkungan (Bandura, 1977, 1986, 1995, 2006). Bandura (2006) menyatakan bahwa efikasi diri merupakan kunci sumberdaya pribadi dalam proses pengembangan diri, adaptasi, dan perubahan. Efikasi diri mempengaruhi proses kognitif, afektif, motivasional, dan pengambilan keputusan individu.

Bandura (1977,1986) menyatakan bahwa dimensi efikasi diri terdiri atas tiga dimensi, yakni (1) Tingkat kesulitan tugas (magnitude), yakni dimensi yang berkaitan dengan tingkat kesulitan tugas. Dimensi ini menekankan bahwa individu cenderung memilih tugas berdasarkan tingkat kesulitannya; (2) Kekuatan (strenght), yakni dimensi yang menekankan pada sejauh mana keyakinan individu dalam melaksanakan tugas dengan sebaik mungkin; (3) Generalisasi (generality), yakni dimensi yang berkaitan dengan keyakinan individu dalam menyelesaikan tugas-tugas tertentu dengan baik dan tuntas, sementara masih ada tugas lain yang perlu diselesaikan.

Sumber efikasi diri terdiri atas empat, yaitu: (1) Pencapaian prestasi (performance accomplishment), merupakan sumber yang paling mendasar sebab berasal dari pengalaman yang bersumber dari pengalaman pribadi mengenai kesuksesan yang pernah dialami. Pengalaman tersebut dapat menjadi ukuran sejauh mana tingkat efikasi diri individu. Hal tersebut dapat menjadi acuan bagi individu untuk senantiasa termotivasi meraih kesuksesan dan mengatasi kegagalan yang dialami individu; (2) Pengalaman yang mewakili (vicarious experience), yakni pengalaman yang berasal dari pengalaman diri sendiri dan orang lain dapat memberikan informasi mengenai kemampuan memprediksi dan mengatasi ancaman-ancaman untuk mengembangkan dan membuktikan tingkat efikasi diri yang kuat. Keberhasilan akan meningkatkan efikasi diri, sebaliknya kegagalan akan menurunkan efikasi diri; (3) Persuasi verbal (verbal persuasion), yakni dapat berasal dari diri sendiri dan orang lain. Individu dapat meyakinkan diri sendiri dan orang lain dapat mempengaruhi individu 
untuk melakukan sesuatu ; (4) Dorongan emosional (emotional arousal), memperhatikan tingkat efikasi diri dengan memperhatikan reaksi emosi. Individu yang cemas cenderung mengantisipasi kegagalan. Seringkali sumber ini disebut juga dengan informasi fisiologis, yakni evaluasi diri dari kondisi fisiologis dan emosional. Kondisi fisik dan emosi yang seringkali muncul dalam diri individu merupakan respon terhadap kejadian sekitar dalam bentuk isyarat tertentu, sehingga berdampak pada munculnya persepsi individu terhadap kemampuan yang dimilikinya dalam menyelesaikan tugas. Dengan mengubah persepsi menjadi lebih positif, maka efikasi diri individu juga lebih tinggi (Bandura, 1977).

\section{Metode Penelitian}

\section{Subjek Penelitian}

Subjek penelitian ini adalah perawat pelaksana rumah sakit umum daerah di salah satu kabupaten di Sulawesi Selatan. Jumlahnya ada 10 orang. Status mereka adalah pegawai negeri sipil. Mereka telah bekerja di rumah sakit minimal 1 tahun, pendidikan minimal D3 Keperawatan. Subjek penelitian ini terbagi dalam dua kelompok 5 orang kelompok eksperimen dan 5 orang untuk kelompok kontrol. Mereka berasal dari ruang perawatan interna (I dan VII), anak (II), dan bedah (V). Mereka adalah perawat pelaksana yang memiliki tingkat keterikatan kerja kategori sedang. Penelitian kuasi eksperimen ini menggunakan desain eksperimen ulang non-random (non-randomized pretestposttest control group design).

\section{Metode Pengumpulan Data}

Ada dua skala alam penelitianini, yakni Utrecht Work Engagement Scale (UWES) untuk mengukur keterikatan kerja dan skala efikasi diri untuk mengukur efikasi diri. Skala UWES yang digunakan merupakan adaptasi dari Christian, Hastjarjo, Ancok, dan Meiyanto (2013). UWES disusun berdasarkan tiga aspek, yaitu semangat, dedikasi, dan penghayatan. Skala efikasi diri disusun Valentino dan Himam (2013) menggunakan dimensi efikasi diri yang diungkapkan Bandura $(1977,1986)$, yakni tingkat kesulitan tugas, kekuatan, dan generalisasi.

Pada penelitian ini, wawancara digunakan dalam proses pengumpulan data awal dan pengumpulan data tambahan setelah pemberian intervensi. Wawancara pada pengumpulan data awal berfokus pada permasalahan keterikatan kerja. Wawancara pada pengumpulan data tambahan berfokus pada manfaat yang didapatkan oleh subjek setelah menerima pelatihan efikasi diri. Observasi dilakukan pada pelaksanaan pemberian perlakuan terhadap kelompok eksperimen. Hal-hal yang diobservasi adalah perilaku yang ditunjukkan subjek penelitian selama proses pelatihan.

\section{Analisis Data}

Teknik analisis data yang digunakan adalah uji Mann-Whitney, yakni analisis yang membandingkan nilai skor yang diperoleh antara kelompok eksperimen dan kontrol. Skor yang dimaksud adalah skor selisih antara skor pascates dengan prates. Skor yang dimaksud adalah skor selisih antara skor pascates dengan prates. Peneliti juga menggunakan uji Friedman sebagai analisis data tambahan untuk menganalisis skor yang diperoleh kelompok eksperimen pada tiga kali pengukuran, yakni prates, pascates, dan tindak lanjut (Seniati, Yulianto, dan Setiadi,2005).

\section{Prosedur Intervensi}

Prosedur intervensi meliputi tahap persiapan, pelaksanaan dan tahap analisis data. Tahap persiapan meliputi perizinan Tahapan ini dimulai dengan menghubungi rumah sakit untuk keperluan izin penelitian, 
persiapan alat ukur penelitian, Ujicoba modul. Proses pelaksanaan meliputi prates- pascates, dan terakhir pengambilan data tindak lanjut.

\section{Hasil Penelitian}

Tabel 1. Deskripsi Subjek Penelitian

\begin{tabular}{cccc}
\hline No. & Inisial & Jenis Kelamin & Lama Bekerja \\
\hline & & Kelompok Eksperimen & \\
\hline 1 & NW & Perempuan & 7 tahun \\
2 & SW & Perempuan & 6 tahun \\
3 & AN & Perempuan & 10 tahun \\
4 & SS & Perempuan & 15 tahun \\
5 & RD & Perempuan & 6 tahun \\
\hline & Kelompok Kontrol & 18 tahun \\
\hline 1 & NH & Perempuan & 7 tahun \\
2 & MI & Perempuan & 17 tahun \\
3 & HR & Perempuan & 14 tahun \\
4 & SN & Perempuan & 8 tahun \\
5 & RH & Perempuan &
\end{tabular}

Tabel 2. Deskripsi Data Penelitian Kelompok Eksperimen

\begin{tabular}{cccccc}
\hline Variabel & Tahap & Min & Max & Mean & SD \\
\hline \multirow{2}{*}{ Keterikatan } & Prates & 75 & 80 & 78,40 & 2,07 \\
Kerja & Pascates & 76 & 100 & 86,40 & 10,43 \\
& Tindak Lanjut & 76 & 96 & 86 & 8,86 \\
\multirow{2}{*}{ Efikasi Diri } & Prates & 48 & 54 & 51 & 2,23 \\
& Pascates & 44 & 55 & 51,20 & 4,20 \\
& Tindak Lanjut & 49 & 57 & 52,80 & 2,19 \\
\hline
\end{tabular}

Tabel 3. Deskripsi Kategori Skor Keterikatan Kerja Kelompok Eksperimen

\begin{tabular}{ccccc}
\hline \multirow{2}{*}{ No. } & Inisial & \multicolumn{3}{c}{ Skor/Kategori } \\
\cline { 3 - 5 } & & Prates & Pascates & $\begin{array}{c}\text { Tindak } \\
\text { Lanjut }\end{array}$ \\
\hline 1 & NW & 78/Sedang & 88/Sedang & 76/Sedang \\
2 & RD & 79/Sedang & 100/Tinggi & 96/Tinggi \\
3 & AN & 75/Sedang & 92/Tinggi & $94 /$ Tinggi \\
4 & SS & 80/Sedang & $76 /$ Sedang & $79 /$ Sedang \\
5 & SW & 80/Sedang & 76/Sedang & 85/Sedang \\
\hline
\end{tabular}

Tabel 4. Deskripsi Data Kelompok Kontrol

\begin{tabular}{cccccc}
\hline Variabel & Tahap & Min & Max & Mean & SD \\
\hline Keterikatan & Prates & 76 & 88 & 80,8 & 4,60 \\
Kerja & Pascates & 74 & 84 & 80 & 4,69 \\
\multirow{2}{*}{ Efikasi Diri } & Prates & 47 & 53 & 49,8 & 2,38 \\
& Pascates & 47 & 52 & 49 & 2,73 \\
\hline
\end{tabular}


Tabel 5. Deskripsi Kategori Skor Keterikatan Kerja Kelompok Kontrol

\begin{tabular}{cccc}
\hline \multirow{2}{*}{ No. } & \multirow{2}{*}{ Inisial } & \multicolumn{2}{c}{ Skor/Kategori } \\
\cline { 3 - 4 } & & Prates & Pascates \\
\hline 1 & HR & $76 /$ Sedang & $84 /$ Sedang \\
2 & MI & 82/Sedang & $74 /$ Sedang \\
3 & NH & 88/Sedang & 88/Sedang \\
4 & SN & 88/Sedang & $75 /$ Sedang \\
5 & NS & $78 /$ Sedang & $76 /$ Sedang \\
\hline
\end{tabular}

Tabel 6. Hasil Uji Mann-Whitney

\begin{tabular}{ccccc}
\hline Variabel & Tahap & Z & P & Keterangan \\
\hline Keterikatan & Prates & $-0,84$ & 0,19 & Tidak Signifikan \\
Kerja & Pascates & $-1,16$ & 0,12 & Tidak Signifikan \\
Efikasi Diri & Prates & $-0,84$ & 0,19 & Tidak Signifikan \\
& Pascates & $-1,20$ & 0,11 & Tidak Signifikan \\
\hline
\end{tabular}

Tabel 7. Hasil Uji Mann-Whitney Per Aspek

\begin{tabular}{|c|c|c|c|c|c|}
\hline Variabel & Aspek & Tahap & $\mathbf{Z}$ & $\mathbf{P}$ & Keterangan \\
\hline \multirow{6}{*}{$\begin{array}{c}\text { Keterikatan } \\
\text { Kerja }\end{array}$} & \multirow{2}{*}{ Semangat } & Prates & $-0,94$ & 0,17 & Tidak Signifikan \\
\hline & & Pascates & $-0,14$ & 0,08 & Tidak Signifikan \\
\hline & \multirow{2}{*}{ Dedikasi } & Prates & $-0,21$ & 0,41 & Tidak Signifikan \\
\hline & & Pascates & $-2,14$ & 0,01 & Signifikan \\
\hline & \multirow{2}{*}{ Penghayatan } & Prates & $-2,02$ & 0,02 & Signifikan \\
\hline & & Pascates & $-0,42$ & 0,33 & Tidak Signifikan \\
\hline \multirow{6}{*}{ Efikasi Diri } & Tingkat & Prates & $-1,16$ & 0,12 & Tidak Signifikan \\
\hline & Kesulitan Tugas & Pascates & $-1,39$ & 0,08 & Tidak Signifikan \\
\hline & \multirow{2}{*}{ Kekuatan } & Prates & $-1,64$ & 0,05 & Tidak Signifikan \\
\hline & & Pascates & $-1,47$ & 0,07 & Tidak Signifikan \\
\hline & \multirow{2}{*}{ Generalisasi } & Prates & $-0,43$ & 0,33 & Tidak Signifikan \\
\hline & & Pascates & $-0,22$ & 0,41 & Tidak Signifikan \\
\hline
\end{tabular}

Tabel 8. Hasil Uji Friedman

\begin{tabular}{ccccc}
\hline Varibel & Tahap & Chi-Square & P & Keterangan \\
\hline $\begin{array}{c}\text { Keterikatan } \\
\text { Kerja }\end{array}$ & $\begin{array}{c}\text { Prates, Pascates, } \\
\text { Tindak Lanjut }\end{array}$ & 1,60 & 0,44 & Tidak Signifikan \\
\hline Efikasi Diri & $\begin{array}{c}\text { Prates, Pascates, } \\
\text { Tindak Lanjut }\end{array}$ & 0,47 & 0,70 & Tidak Signifikan \\
\hline
\end{tabular}

Tabel 9. Hasil Uji Friedman Per Aspek

\begin{tabular}{ccccc}
\hline Varibel & Aspek & Chi-Square & P & Keterangan \\
\hline \multirow{2}{*}{$\begin{array}{c}\text { Keterikatan } \\
\text { Kerja }\end{array}$} & Semangat & 2,11 & 0,34 & Tidak Signifikan \\
\cline { 2 - 5 } & Dedikasi & 4,42 & 0,10 & Tidak Signifikan \\
\cline { 2 - 5 } & Penghayatan & 5,20 & 0,07 & Tidak Signifikan \\
\hline \multirow{3}{*}{ Efikasi Diri } & Tingkat Kesulitan Tugas & 0,73 & 0,69 & Tidak Signifikan \\
\cline { 2 - 5 } & Kekuatan & 4,77 & 0,09 & Tidak Signifikan \\
\cline { 2 - 5 } & Generalisasi & 3,64 & 0,16 & Tidak Signifikan \\
\hline
\end{tabular}




\section{Pembahasan}

Penelitian ini berfokus pada pengaruh pelatihan efikasi diri terhadap keterikatan kerja perawat di salah satu rumah sakit umum daerah di Sulawesi Selatan. Hipotesis penelitian ini adalah pelatihan efikasi diri berpengaruh dalam meningkatkan keterikatan kerja perawat rumah sakit umum daerah di salah satu kabupaten di Sulawesi Selatan. Hasil analisis data menunjukkan bahwa hipotesis penelitian ini ditolak. Hal ini didasarkan hasil analisis data pada varibel keterikatan kerja dan efikasi diri, baik menggunakan uji Mann-Whitney maupun uji Friedman untuk masing-masing variabel dan aspeknya.

Hipotesis penelitian ini ditolak disebabkan beberapa hal yakni beberapa agenda kegiatan tidak dilaksanakan sesuai dengan modul pelatihan yang telah disusun, sehingga waktu pelaksanaan pelatihan juga kurang dari waktu yang telah ditentukan pada modul pelatihan. Hal ini dapat dilihat dari hasil evaluasi reaksi mengenai waktu pelaksanaan pelatihan, sebagian besar peserta yakni sebesar 90,90 persen peserta menyarankan waktu pelatihan perlu ditambah lagi. Pelaksanaan agenda pelatihan yang tidak sesuai dengan modul, yakni prosedur pengisian lembar kerja Johari Windows pada sesi kedua, tidak dilaksanakannya games "Penjelajah Bulan" dan pengisian lembar kerja strategi pemecahan masalah pada sesi ketiga, padahal materi-materi ini disusun berdasarkan salah satu sumber efikasi diri yakni pencapaian prestasi (performance accomplishment). Selain itu, pada sesi keempat, sharing session, pelaksanaannya lebih cepat dibandingkan durasi waktu yang telah ditentukan sebelumnya. Hal ini terjadi karena narasumber, yang merupakan perawat senior yang menjabat sebagai kepala ruangan perawatan memiliki agenda yang padat pada hari pelaksanaan pelatihan, padahal materi ini disusun dari dua sumber efikasi diri yakni persuasi verbal (verbal persuasion) dan pengalaman yang mewakili (vicarious experience). Tidak hanya itu, games "Energi Positif" pada sesi kelima yang tidak dilaksanakan dan pemberian keterampilan relaksasi yang berbeda dengan modul pelatihan juga berdampak pada tidak adanya perbedaan skor keterikatan kerja dan efikasi diri perawat pada pengukuran prates, pascates, dan tindak lanjut pada kelompok eksperimen, padahal materi-materi ini disusun dari salah satu sumber efikasi diri yakni dorongan emosional (emotional arousal).

\section{Simpulan dan Saran}

Berdasarkan hasil dan pembahasan penelitian, dapat disimpulkan bahwa hipotesis penelitian ditolak yakni pelatihan efikasi diri tidak berpengaruh dalam meningkatkan keterikatan kerja perawat rumah sakit umum daerah di salah satu kabupaten di Sulawesi Selatan. Saran bagi rumah sakit, seyogyanya mengadakan analisis kebutuhan pelatihan kepada para perawat untuk menjadi dasar pemberian pelatihan yang serupa dengan penelitian ini, agar dapat lebih meningkatkan performansi kinerja perawat. Pelatihan yang semacam ini perlu seringkali dilakukan sebagai bentuk strategi pengembangan sumber daya manusia di rumah sakit, khususnya perawat. Selain itu, pihak rumah sakit juga perlu menindaklanjuti penelitian ini dengan melakukan evaluasi tahap perilaku (behavior), hasil (result), dan ROTI (Return On Training Investment). Bagi subjek penelitian,sebaiknya pengetahuan yang telah diperoleh dari pelatihan efikasi diri diterapkan dalam kehidupan kerjanya agar menunjukkan kinerja yang lebih baik lagi. Bagi peneliti selanjutnya, sebaiknya memperhatikan kekurangan penelitian pada hasil evaluasi yang telah dipaparkan 
peneliti, meliputi pemateri, materi, dan metode yang digunakan dalam pelatihan. Peneliti disarankan untuk melaksanakan pelatihan sesuai dengan modul pelatihan yang telah disusun peneliti. Selain itu, sebaiknya peneliti selanjutnya melakukan koordinasi yang lebih baik lagi dengan pihak manajemen rumah sakit, kepala ruangan, dan perawat pelaksana. Peneliti selanjutnya juga disarankan agar dapat melakukan evaluasi tahap perilaku (behavior), hasil (result), dan ROTI (Return On Training Investment). Peneliti selanjutnya juga diharapkan melakukan proses matching ketika menentukan subjek sejak awal, agar kelompok eksperimen dan kelompok kontrol homogen.

\section{Daftar Pustaka}

Alzyoud, A. A., Othman, S. Z., \& Isa, M. F. M. (2014). Examining the role of job resources on work engagement in the academic setting. Journal of Asian Social Science, 11(3), 103-110.

Bakker, A. B. (2011). An-evidence based model of work engagement. Current Directions in Psychological Science,20(4), 265-269.

Bakker, A. B., \& Demerouti, E. (2008). Towards a model of work engagement. Journal of Career Development International, 13(3), 209-223.

Bakker, A. B., \& Schaufeli, W. B. (2014). Work engagement. New York: John Wiley \& Son. Inc.

Bakker, A. B., Schaufeli, W. B., Leiter, M. P., \& Taris, T. W. (2008). Work engagement: An emerging concept in occupational health psychology. Journal of Work and Stress, 22(3), 187-200.

Bandura, A. (1986). Social foundations of thought and action: A social cognitive theory. Englewood Cliffs, NJ: Prentice Hall.

Bandura, A. (1977). Self-efficacy: toward unifying theory of behavioral change. Psychology Review, 84(2), 191-215.

Bandura, A. (1995). Self-efficacy in changing societies. Cambridge. Cambridge University Press.
Bandura, A. (2006). Self-efficacy beliefs of adolescents. Greenwich: Information Age Publishing.

Bedarkar, M., dan Pandita, D. (2014). A study on the drivers of employee engagement impacting employee performance. Journal of Social and Behavioral Sciences, 133(1), 106-115.

Christian, F., Hastjarjo, T.D., Ancok, D., \& Meiyanto, S. (2013). Sumberdayasumberdaya organisasional dan sumberdaya-sumberdaya psikologis yang mempengaruhi keterikatan kerja perawat. Disertasi Tidak Diterbitkan. Yogyakarta: Universitas Gadjah Mada.

Daderman, A. M., \& Basinska, B. A. (2016). Job demands, engagement, and turnover intentions in polish nurses: The role of work-family interface. Journal of Frontiers in Psychology, 7, 114.

Davids, A. (2011). The relationship between work engagement, self-efficacy and optimism among call centre agents. Disertasi diterbitkan. Cape Town: University of the Western Cape.

Hobfoll, S. E., Johnson, R. J., Ennis, N., \& Jackson, A. P. (2003). Resource loss, resource gain, and emotional outcomes among inner city woman. Journal of Personality and Social Psychology, 84(3), 632-643. 
Loeb, C. (2016). Self-efficacy at work. Disertasi diterbitkan. Vasteras: Malardalen University Press.

Lorente, L., Salanova, M., Martinez, I. M., \& Vera, M. (2014). How personal resources predict work engagement and self-rated performance among construction workers: A social cognitive perspective. International Journal of Psychology, 49(3), 200-207.

Mache, S., Virtzhum, K., Wanke, A., Groneberg, D.A., Klapp, B.F., Danzer, G. (2014). Exploring the impact of selfefficacy, optimism, organizational resources on work engagement. Journal of Work, 47, 491-500. DOI 10.3233/WOR-131617.

Montgomery, A., Panagopoulou, E., Kehoe, I., \& Valkanos, E. (2011). Connecting organizational culture and quality of care in the hospital: Is job burnout the missing link? Journal of Health Organization and Management, 25(1), 108-123.

Pisanti, R. (2012). Beyond the job demand control (-support) model: explaining stress reactions in nurses. Disertasi diterbitkan. Leiden: Leiden University.

Pisanti, R., Doef, M. V. D., Maes, S., Lazzari, D., \& Bertini, M. (2011). Job characteristic, organizational conditions, and distress well-being among italian and dutch nurses: A cross national comparison. International Journal of Nursing, 48, 829-837.
Prieto, L.L. (2009). General Discussion. . In Exploring the power of self-efficacy at work: Since empirical studies from the social cognitive perspective $(8,147$ 164. Jaume: Universitat Jaume.

Putri, V. P., Priyatama, A.N., Karyanta, N. A. (2015). Hubungan antara efikasi diri dan optimisme dengan keterikatan pada karyawan PT. Bank Tabungan Negara (Persero) Cabang Solo. Jurnal Wacana Psikologi, 67-81.

Schaufeli, W. B. (2013). What is engagement? In C. Truss, K. Alfes, R. Delbridge, A. Shantz, \& E. Soane (Eds.), Employee engagement in theory and practice. London: Routledge.

Schaufeli, W. B. \& Bakker, A. B. (2003). Utrecht Work Engagement Scale: Preliminary Manual. Utrecht: Utrecht University.

Schaufeli, W. B. \& Bakker, A. B. (2004). Job demands, job resources, and their relationship of burnout and work engagement: A multi-sample study. Journal of Organizational Behavior, 25(3), 293-315.

Seniati, L., Yulianto, A \& Setiadi, B,N. (2005). Psikologi Eksperimen. Jakarta: Indeks.

Thian, J. H. M., Kannusamy, P., \& Yobas, P. K. (2013). Stress, positive affectivity, and work engagement among nurses. Singapora Nursing Journal, 40(1), 2433. 
Valentino, R. \& Himam, F. (2013). Efikasi diri untuk meningkatkan optimisme terhadap perncapaian karir karyawan $P K W T$ perusahaan $X$. Tesis Tidak Diterbitkan. Yogyakarta: Universitas Islam Indonesia.
Xanthopoulou, D., Bakker, A. B., Heuven, E., Demerouti, E., \& Schaufeli, W. B. (2008). Working in the sky: A diary study among flight attendants. Journal of Occupational Health Psychology, 13, 345-356.

Xanthopoulou, D., Bakker, A. B., Demerouti, E., \& Schaufeli, W. B. (2007). The role of personal resources in the job demands-resources model. International Journal of Stress and Management, 14, 121-141. 
Dewi Tri Resky Yanti, Fuad Nashori \& Faraz 